\section{A Informatização na Secretaria do Curso de Pós-Graduação da Faculdade de Arquitetura e Urbanismo da Universidade de São Paulo - FAUUSP}

Professor Titular do Departamento de Projeto Presidente da Comissão de Pós-Graduação FAUUSP (de abril de 1991 a fevereiro de 1994)
Resumo

Histórico do curso de pós-graduaçāo da FAUUSP - A Secretaria de Pós-Graduação: a Secretaria de Alunos e Docentes, a Secretaria de Teses e Dissertaçōes e a Secretaria da Comissão de Pós-Graduação. A informatização dos serviços da Secretaria. O Sistema de Gerenciamento de Pós-Graduação, (POSGRAD), o acompanhamento e controle da situação de todos os alunos, professores, departamentos, produção técnica e dados do c'urso. O Sistema de Controle de Circulaçāo de Documentos da Secretaria (Protocolos). O Sistema de Cadastro de Decisōes e Resoluçōes da Comissão de Pós-Graduação (ATAS). Situação e perspectivas.

\footnotetext{
Abstract Short history of the Graduate Course of the Faculty of Architecture and Urbanism of the University of São Paulo - FAUUSP - at master's and doctorate's level. The Secretary of the Graduate Course: the Secretary of Students and Professors; the Secretary of Dissertations and Theses; and the Secretary of the Comission of Graduate Course. The information system ("software") of the management of the Graduate Couse (POSGRAD): for storing, retrieving and controling information about students, professors, departments, researches, dissertations, theses, scientific artistic and technical production and data of the course. The information system ("software") of control and follow-up of documents of the Secretary of the Graduate Course (Protocolos). The information system ("software") of the record of decisions and resolutions of the Comission of the Graduate Course (ATAS). Situation and perspectives.
} 
Tabela 1

Corpo Docente

\begin{tabular}{l|l}
\hline Anci & Qtd. Professores \\
\hline 1987 & 55 \\
\hline 1988 & 64 \\
\hline 1989 & 65 \\
\hline 1990 & 66 \\
\hline 1991 & 71 \\
\hline 1992 & 75 \\
\hline 1993 & 79 \\
\hline
\end{tabular}

Tabela 2

Produçao de Dissertaçöes e Teses

\begin{tabular}{l|l|l}
\hline Arıc & $\begin{array}{l}\text { Dissertaçōes } \\
\text { de Mestrado }\end{array}$ & $\begin{array}{l}\text { Teses de } \\
\text { Doutorado }\end{array}$ \\
\hline 1987 & 13 & 14 \\
\hline 1988 & 16 & 9 \\
\hline 1989 & 25 & 15 \\
\hline 1990 & 14 & 11 \\
\hline 1991 & 27 & 12 \\
\hline 1992 & 15 & 15 \\
\hline 1993 & 12 & 17 \\
\hline
\end{tabular}

\section{Histórico do Curso de Pós-Graduação da FAUUSP}

O curso de pós-graduaçāo em Arquitetura e Urbanismo. da Faculdade de Arquitetura e Urbanismo da Universidade de São Paulo, a nível de mestrado foi criado em 1971, sendo a primeira turma admitida em 1973. Em 1980, foi iniciado o curso de pós-graduação a nível de doutorado. tendo sido nesse mesmo ano admitida a primeira turma.

Anualmente são abertas inscriçōes para novos alunos, com expressivo número de candidatos provenientes de diversas instituiçōes universitárias nacionais e do exterior

Desde sua criação o curso tem crescido progressivamente tendo formado 232 mestres e 98 doutores até dezembro de 1993.

$\mathrm{Na}$ Tabela 1 mostramos a evoluçāo do corpo docente, com número crescente de professores orientadores, para ministrar disciplinas e orientar trabalhos de mestrado e/ou doutorado.

Nestes totais estão incluidos os professores colaboradores, aposentados da própria Faculdade, e professores doutores de outras unidades da USP, que, por terem pesquisas em áreas afins as do curso, participam das atividades de pós-graduação.

A produção de dissertaçōes e teses, nos últimos anos, está assim representada. (Vide Tabela 2)

Em 1993. o curso de pós-graduação mantém 402 alunos regulares e 79 professores orientadores em uma área interdepartamental - Estruturas Ambientals Urbanas

\section{Secretaria de Pós-Graduação}

Com o desenvolvımento do curso, crescimento da demanda e a absorção de novos alunos, foi indispensável desenvolver um controle administrativo rigoroso. Para tanto, a estrutura administrativa da Secretaria foi reorganizada a partir de 1989, tendo sido dividida em três blocos:

- Secretaria de Alunos e Docentes,

- Secretaria de Teses e Dissertaçōes, e

- Secretaria da CPG.

A Secretaria de Alunos e Docentes produz e mantém atualizados dados históricos dos alunos quanto às disciplinas cursadas, trabalhos programados desenvolvidos e apresentados, pesquisas em desenvolvimento e realização de exames de qualificação. Mantém também um arquivo de dados dos docentes com as discıplinas lecionadas. alunos orientados e em orıentação e cadastro da produção científica e de pesquisa.

A Secretaria de Teses e Dissertações ocupa-se da implementação das Comissōes Examinadoras das provas de qualificação e defesas de dissertaçōes e teses dentro dos prazos e normas estabelecidas pelo regulamento do curso. além de ocupar-se dos elementos legais e administrativos para a expedição de certificados e títulos de mestre e doutor.

A Secretaria da CPG dá assistência a todas as atividades da Comissão de Pós-Graduação e ocupa-se de viabilizar, com agilidade. os contatos com as agências de fomento federais e estaduais e com a Pró-Reitoria de Pós-Gradua- 
ção da Universidade, além de proceder à coordenação geral dos dois blocos anteriores.

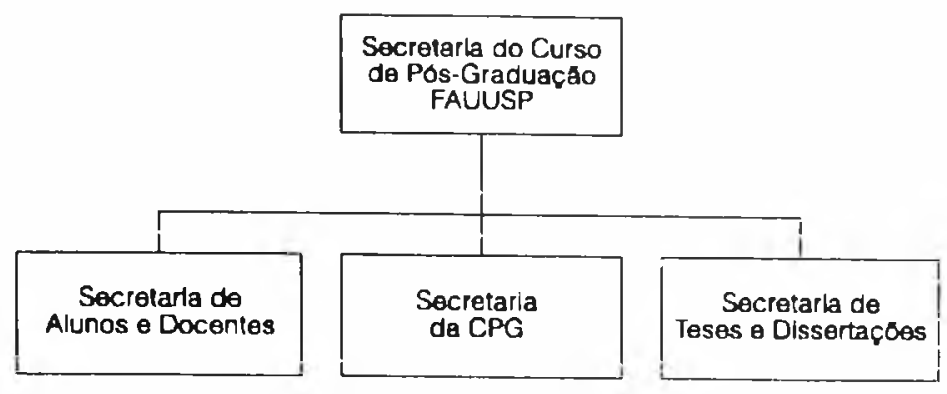

Estas funções são desenvolvidas por funcionários que se prepararam e, de certa forma, se especializaram nessas atividades.

Apesar dessa reorganizaçāo da estrutura administrativa da Secretaria da CPG, que se mantinha até 1990 basicamente a mesma dos anos 70 , havia necessidade urgente de informatizar os trabalhos administrativos e renovar os seus equipamentos de escritório. Apenas em 1989, a Faculdade destinou à Secretaria os primeiros 2 microcomputadores PC-XT para iniciar o processo de informatizaçāo. Neste ano, 1989, o curso já atendia: 201 alunos regulares de mestrado, e 143 de doutorado.

Para aliviar essas deficiências. a CPG. a partir de 1990, tomou as seguintes medidas:

1) reforma e reorganização do espaço destinado à Secretaria da CPG e salas da Presidência e da CPG, com instalaçāo de divisórias funcionais e moveis adequados às funçōes nele exercidas:

2) renovação do material de escritório da Secretaria da CPG;

3) informatização dos trabalhos administrativos.

Para renovação do material, com recursos oriundos da CAPES - Coordenação de Aperfeiçoamento de Pessoal de Nivel Superior do Ministério da Educação e Cultura, entre 1991 a 1994, foram adquiridas máquinas de escrever eletrônica, aparelho de FAX, seis microcomputadores - dois 486, três 386-SX e um AT-286, dos quais dois ligados em rede -, estabilizadores de voltagem. cinco impressoras, sendo três matriciaıs, uma laser e uma desk-jet, e uma copiadora reprográfica.

A informatização dos serviços iniciou-se em 1992, com a elaboração e implantação progressiva de sistemas de processamento de dados ("softwares"), visando facilitar o gerenciamento do curso de pós-graduação. Estes sistemas, montados e implantados pela presidência da CPG, com o auxílio de verbas da CAPES, abrangem basicamente:

- Sistema de Gerenciamento do Curso de Pós-Gradução - "POSGRAD";

- Sistema de Controle de Circulação de Documentos e Apoio à Secretaria "PROTOCOLOS";

- Sistema de Cadastro de Decisões e Resoluções da Comissão de Pós-Graduação - "ATAS"

\section{O Sistema POSGRAD}

O Sistema de Gerenciamento de Pós-Graduação, - "POSGRAD" desenvolvido através de assessoria com a "Pégasus Soluçōes" tem por objetivo suprir a Secretaria do curso de pós-graduaçāo da FAUUSP com as melhores condi- 
ções para efetuar o acompanhamento e controle da situação de todos seus alunos, professores, departamentos, da produção técnica e outros dados diretamente relacionados ao curso.

Devido às suas características muito particulares, o sistema POSGRAD foi desenvolvido "sob medida" para atender aos objetivos propostos, com uso da linguagem "Clipper" e em quatro etapas:

a. Desenvolvimento do sistema de gerenciamento de dados do corpo discente, e controle de créditos;

b. Desenvolvimento do sistema de gerenciamento de dados do corpo docente, e de produção;

c. Implantação de ambos sistemas, com digitação de massa de dados e integração com o "EXECAPES";

d. Treinamento do pessoal da secretaria.

Ao longo de seu desenvolvimento e implantação, diversas melhorias foram introduzidas, com o objetivo de ampliar os produtos do sistema e otimizar sua operação.

O sistema "POSGRAD", subdivide-se nos seguintes módulos:

\subsection{Módulo de cadastros básicos}

Contém rotinas para cadastramento e manutenção de dados gerais que serão aplicados nos diversos processos de controle:

- Corpo Discente: ficha cadastral de dados de todos alunos (especiais ou regulares);

- Corpo Docente: cadastro de dados de todos professores (visitantes ou permanentes - exclusivos ou não);

- Subáreas/Opções de Estudo e Pesquisa: cadastro de dados de todas subáreas;

- Disciplinas: cadastro de todas disciplinas lecionadas;

- Departamentos: cadastro dos departamentos.

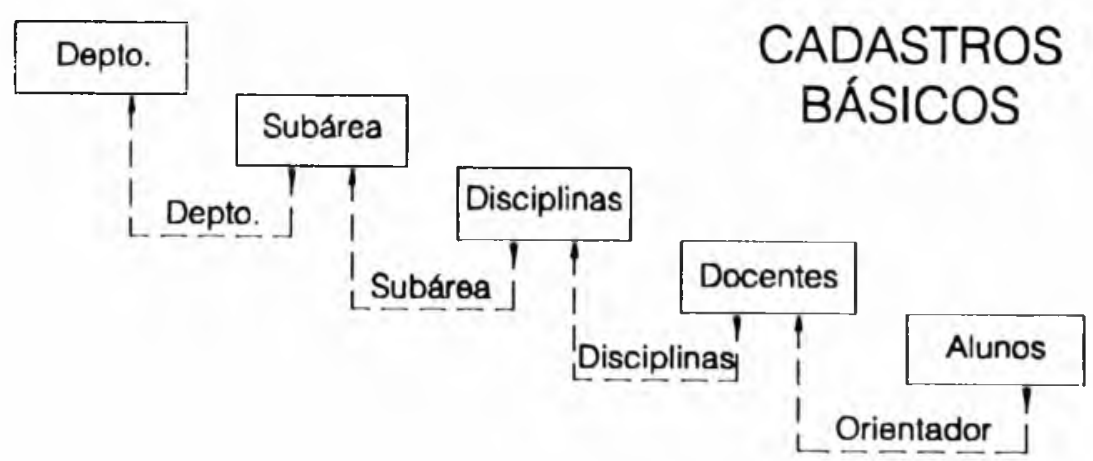

\subsection{Módulo de controle curricular e produção}

Abrange todos os dados necessários para o controle curricular e de produção relacionada à pós-graduação, incluindo:

- Inscriçōes para seleção: dados dos pretendentes ao curso de pós-graduação e que se inscreveram no processo de seleção;

- Exames de proficiência em língua estrangeira: dados sobre resultados dos exames;

- Matrículas (e outras operações): dados sobre os alunos matriculados no curso e em cada disciplina, trancamentos, abandono; 
- Avaliações das disciplinas: registro das avaliaçōes (notas) obtidas pelos alunos e indicação de aprovação;

- Controle de presenças: registro das presenças dos alunos e verificação do percentual de presença;

- TP's (Trabalhos Programados): cadastramento dos trabalhos programados com suas principais referências;

- Exames de Qualificação: resultados dos exames e a constituição de suas bancas;

- Teses e Dissertaçōes: cadastramento das teses e dissertaçōes com títulos, resumos e abstracts e bancas;

- Pesquisas e Publicaçōes: cadastramento da produção cientifica do corpo docente e discente (módulo estanque, cuja cópia pode ser instalada no microcomputador da biblioteca).

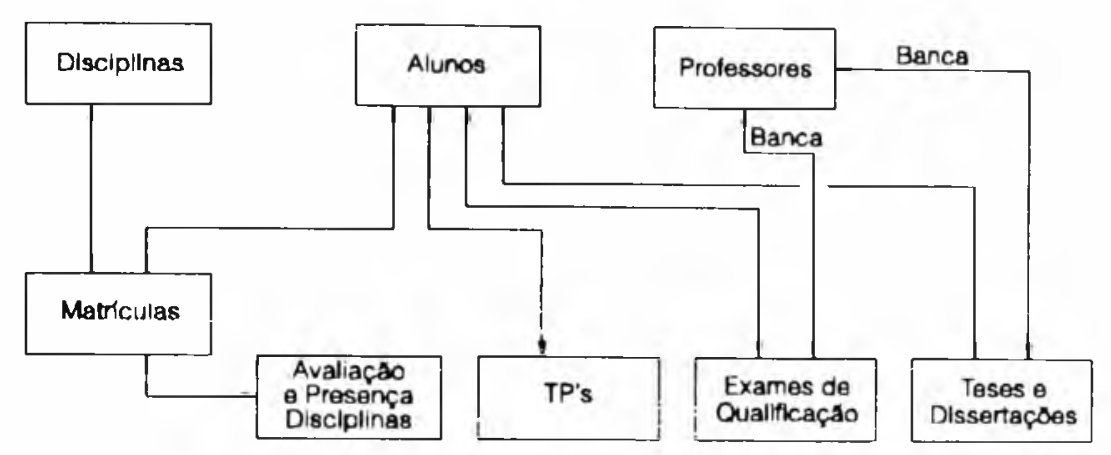

\subsection{Módulo de consultas}

Permite consultas no monitor ou emissão de relatórios individuais sobre a situação de:

- Alunos - mostra sua situação: disciplinas cumpridas, créditos acumulados, TP's, exames, datas, etc.

- Professores - mostra sua situação: cadastramento. orientaçōes, avaliações, produção. etc.

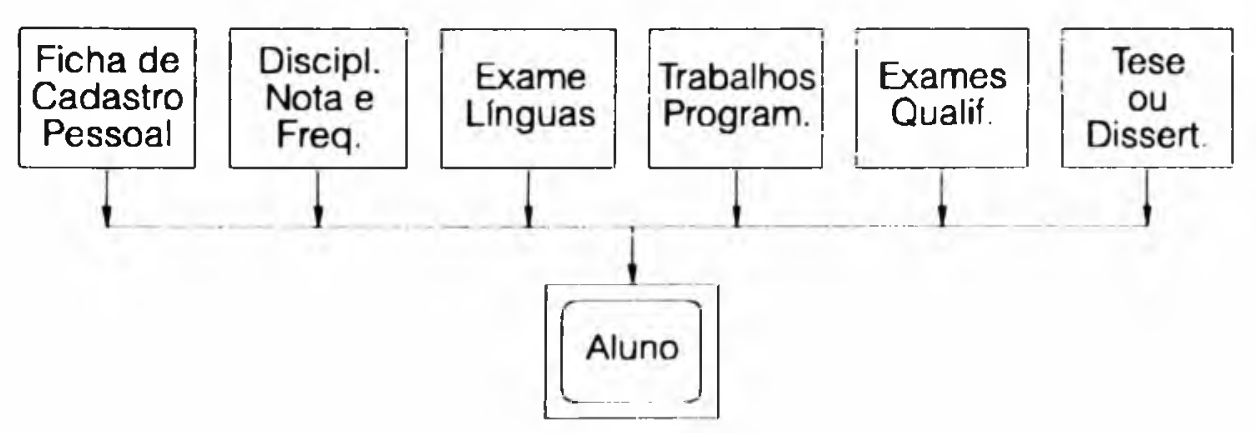

\subsection{Módulo de estatísticas}

Rotinas de processamento lógico com classificaçāo das informaçōes, gerando diversos tipos de relatórios gerenciais e estatísticos para auxílio à tomada de decisão.

\subsection{Outras características}

O sistema conta ainda com um módulo secundário de utilitários que contém rotinas para auxilio ao usuário: cópia de segurança e recuperação de arquivos, reindexação de arquivos, exportação de dados para sistema EXECAPES. 
Tabela 3

\begin{tabular}{l|l}
\hline Tipo de Ficha Cadastral & $\begin{array}{l}\text { Qtde. de } \\
\text { Registros }\end{array}$ \\
\hline Alunos & 771 \\
\hline $\begin{array}{l}\text { Professores, Integr. Bancas. } \\
\text { Pesquisadores }\end{array}$ & 470 \\
\hline Teses e Dissertaçōes & 285 \\
\hline Publicaçōes & 773 \\
\hline Pesquisas & 182 \\
\hline
\end{tabular}

O EXECAPES é um software da CAPES - Coordenação de Aperfeiçoamento do Pessoal de Nivel Superior, do Ministério da Educaçāo e Cultura, voltado para o cadastramento e avaliação de cursos de pós-graduaçāo do país.

No desenvolvimento do POSGRAD foi estabelecida uma troca de dados (arquivos) com o sistema QUIRON da Reitoria da USP permitindo a atualização simultânea dos dois sistemas.

É importante observar que o sistema POSGRAD foi montado para permitir o processamento em rede, multiusuário. Assim, ele admite compartilhamento de arquivos e uso simultâneo por diferentes usuários.

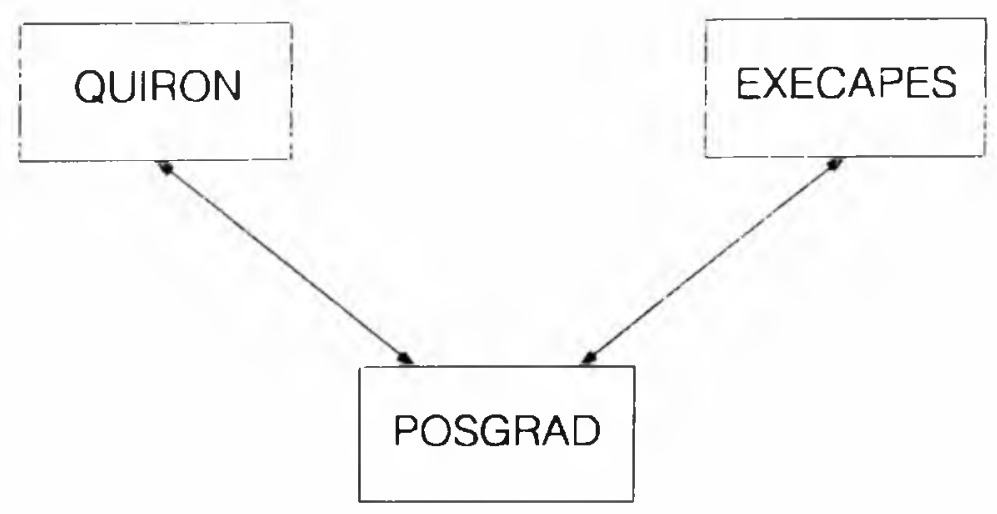

\subsection{Base de dados}

Atualmente, o POSGRAD já acumula significativa massa de dados. (Vide Tabela 3)

Com a consolidaçāo destes dados, inúmeros benefícios estão disponívieis para os usuarios da Secretaria de Pós-Graduação FAUUSP.

- Matriculas de alunos.

- Emissão de relatório ou consulta em tela ımediata. sobre a sıtuação curricular ou produção científıca.

- Emissão automática de atestados e históricos.

- Agilização no atendimento de balcão, eliminando necessidade de busca de dados em arquivos manuais.

- Agilidade na emissāo de dados para órgāos controladores (CAPES, Reitoria, etc.)

- Rapidez na localizaçāo de históricos.

\section{Sistema de Controle de Circulação de Documentos da Secretaria - (Protocolos)}

Com assessoria da "Pégasus Soluções" este sistema foi programado em Clipper e teve por objetivo implantar um método automatizado para controle de toda circulação de documentos na Secretaria da CPG: entradas, saídas, distribuiçāo, andamento e malotes. Além disso o sistema automatizou a emissão de protocolos e guias.

O sistema foi implantado em três etapas:
a. Desenvolvimento do sistema:
b. Digitacão e transferência de dados de 1991 e 1992.
c. Implantação e treinamento. 
O sistema é subdividido nos seguintes módulos:

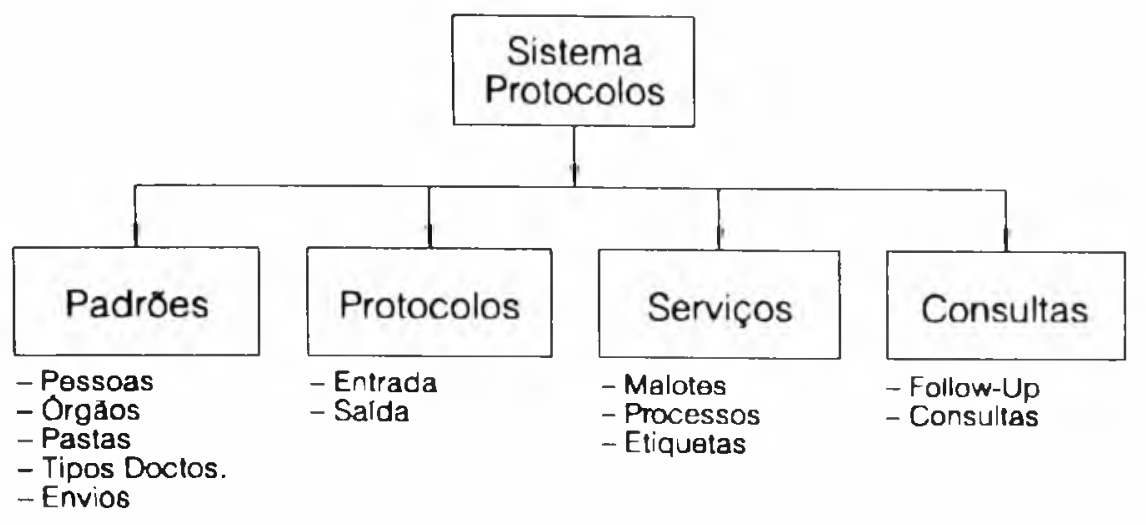

\subsection{Módulo de padröes de referências}

Contém dados utilizados com freqüência e que são utilizados sem necessidade de nova digitação, incluindo:

- Pessoas/órgāos: dados de pessoas ou órgāos corn os quais a Secretaria mantém troca de correspondência;

- Pasta-Arquivo: indice das pastas do arquivo da Secretaria da CPG;

- Tipos de Documentos: códigos de classificação de tipos de documentos utilizados;

- Forma Envio: códigos das formas de envio da correspondência da CPG.

\subsection{Módulo de protocolos}

Onde o usuário cadastrará os dados, emitindo os protocolos de recebimento ou expedição de documentos.

\subsection{Módulo de serviços}

Executa tarefas básicas para a Secretaria:

- Malotes: preparação de relação de documentos enviados através do malote;

- Processos: controle de andamento dos processos da Reitoria;

- Etiquetas: impressão de etiquetas para correspondências.

\subsection{Módulo de consultas e de "follow-up"}

Inclui rotinas de consulta no monitor ou impressão de relatórios de "agenda" ou "follow-up" (acompanhamento) em classificados por pessoa ou órgão, data, assunto ou palavra-chave.

\subsection{Módulo de utilitários}

Auxilia o usuário em atividades básicas de operação do micro, dispensando quaisquer conhecimentos específicos para executar cópias de segurança, recuperação e reindexação de arquivos.

Os benefícios práticos do sistema para a Secretaria de Pós-Graduação são os seguintes:

- Agilização na busca e consulta de protocolos.

- Padronização na execução de atividades.

- Emissão automatizada de documentos. 


\section{Sistema de Atas}

O sistema de Cadastro de Decisões e Resoluções da Comissão de Pós-Graduaçāo, denominado "ATAS" foi desenvolvido com a assessoria da firma "NEWAY Sistemas e Informaçōes" com o objetivo básico de dinamizar o acesso às informaçōes contidas nas atas de reuniōes da CPG da FAUUSP visto que a localizaçāo de um determinado tópico, num grande volume de texto e papel é sempre uma tarefa difícil.

Para que o sistema pudesse se tornar uma ferramenta útil, ele deveria aproximar-se ao máximo do método de pesquisa tradicional, sem que tivéssemos que introduzir códigos especiais para busca ou outros artificios muito comuns em sistemas de computadores.

A melhor solução pensada foi a de classificar as informaçōes como fazemos manualmente, isto é, fomos analisar como as informações são naturalmente organizadas e reproduzimos esse sistema no computador. Desta forma, a informação é classificada através de dois índices principais: o tópico e a chave.

O tópico refere-se ao assunto tratado por aquela informaçāo, ou seja, se estivermos tratando de "Trancamento de Matrícula" esse é o tópico ao qual iremos relacionar a informação, pois normalmente essa é uma das formas pela qual essa informação será procurada.

Quando procuramos informações de algum tópico, por exemplo, "Trancamento de Matricula" procuramos algum item específico e, desta forma, criamos uma chave de consulta, que consiste numa segunda classificação de um determinado tópico. Assim. o trancamento de matricula do aluno MARIO DA SILVA, foi classificado com as seguintes características:

Tópico: TRANCAMENTO DE MATRÍCULA

Chave: MARIO DA SILVA

Isto feito, um outro recurso surge naturalmente: a classificação das informaçōes através de CHAVE e TÓPICO, o que possibilita que localizemos rapidamente qualquer informação sobre uma determinada CHAVE, independentemente do tópico. Temos então a possibilidade de relacionar tacilmente todas as informações, como no exemplo:

Chave: MARIO DA SILVA

Tópicos: TRANCAMENTO DE MATRÍCULA BANCA DE EXAME PRORROGAÇÃO DE PRAZOS

Temos então um sistema capaz de localizar rapidamente qualquer informação contida nas atas, utilizando uma dupla classificação dessa informaçāo.

Atas

Tópicos

Chaves

Informaçōes

Com essa estrutura foi possivel elaborar um sistema que de forma bastante rápida pudesse localizar e exibir (ou imprimir) trechos de atas através de três classifıcaçōes distintas: por ata, por tópico ou por chave, sempre de forma encadeada. 
Tecnicamente, o sistema foi desenvolvido em linguagem Dataflex, versão 3.0. devido a sua grande capacidade de manipular dados com extrema rapidez e devido à sua portabilidade, isto é, esse mesmo sistema pode ser instalado desde em um simples PC-XT até em equipamentos HP ou AS-400 da IBM, passando pelas redes locais e supermicros, bastando apenas recompilá-lo.

Três módulos básicos formam o sistema: Entrada de Dados, Pesquisa e Relatórios.

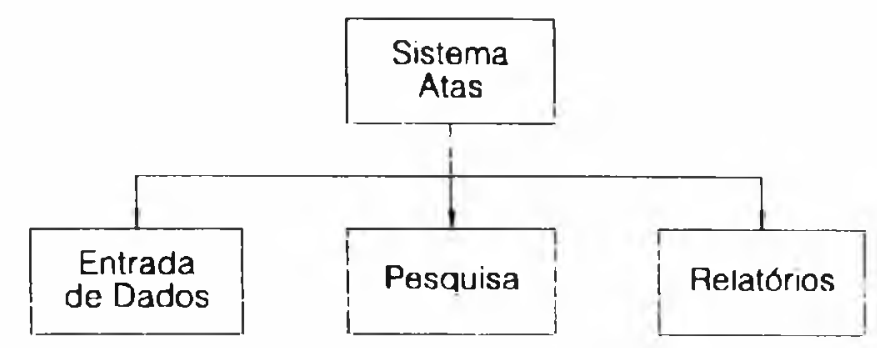

O Módulo de Entrada de Dados constitui-se de uma tela para digitação dos dados (transcrição de textos de atas), onde as informaçōes são classificadas, assinalando-se os tópicos, as palavras-chaves e identificadores do documento, tais como número e data da ata.

O Módulo de Pesquisa é o coração do sistema. consistindo de programas que, através do fornecimento do tópico, da palavra-chave ou do identificador do documento, traz o mesmo à tela ou indica sua ocorrência em um tipo de "índice remissivo"

O Módulo de Relatórios é uma decorrência direta do módulo de pesquisa. apresentando as informações em mídıa ımpressa.

O sistema ATAS foi desenvolvido em três etapas:

a. desenvolvimento do sistema enquanto "software";

b. implantação do sistema, com digitação de dados referentes aos últimos cinco anos;

c. treinamento do pessoal da Secretaria.

A implantação do sistema trouxe diversos beneficios à Secretaria de Pós-Graduação:

- Agilização na pesquisa e localızação de informações das atas;

- Possibilidade de qualquer funcionário buscar estes dados, antes restritos apenas a um funcionário;

- Formação de banco de dados, extremamente útil para a administração e controle das ações determinadas nas atas.

\section{Situação e Perspectivas}

Atualmente prosseguem as atividades de ajustes, revisões e consolidação dos sistemas, treinamento ou reciclagem dos funcionários e testes em situações reals.

Ao mesmo tempo, a presidência da CPG já está elaborando planos para a ampliação do processo de informatização, prevendo:

- Aquisiçāo de novos "softwares" (última geração). 
- Treinamento.

- Ampliação das bases de dados (cadastramento de dados antigos que não foram digitados na $1^{\underline{a}}$ etapa).

- Interligação entre sistemas, especialmente com o novo sistema de Informatização da pós-graduaçāo da USP - sistema FÊNIX.

\section{Colaboradores}

Fábio Rendelucci

- analista-senior, responsável pelo Sistema de Atas, gerente da NEWAY Sistemas e Informações SC Ltda.

Irvando Luis Particelli

- engenheiro e analista de sistemas, responsável pelos Sistemas Posgrad e Protocolos, gerente da Pégasus Soluções SC Ltda. 